\title{
Placental Malaria Parasitization at Delivery: Experience at a Nigerian Tertiary Hospital
}

\author{
Oweisi P.W., MBBS, FWACS \\ John C.T., MBBS, FWACS, FMCOG, FRCOG, FICS \\ Omietimi J.E., B Med Sc., MBBS, FWACS \\ Aigere E.O.S., MBBS, FWACS, FMCOG, DMAS \\ Allagoa D.O., B Med (Pharm), MBBS, FWACS, FMAS, Cert \\ ART, Dip HSM, FICS \\ Kotingo E.L., MBBS, DMAS, FMAS, FWACS \\ Department of Obstetrics and Gynaecology, Federal Medical Centre, \\ Yenagoa, Bayelsa State, Nigeria
}

Doi: 10.19044/esj.2018.v14n9p243 URL:http://dx.doi.org/10.19044/esj.2018.v14n9p243

\begin{abstract}
Background: In malaria endemic areas, pregnant women are constantly at risk of repeated malaria infestation which if left untreated, poses a significant threat to the health and survival of the mother and her baby. Objective: This study determined the prevalence and risk factors for placental malaria parasitaemia among parturients at the Federal Medical Centre, Yenagoa, Nigeria. Methodology: A prospective cross-sectional analytical study of 205 parturients recruited consecutively at presentation for delivery. An interviewer-administered questionnaire was used to collect data. After delivery, placental blood was collected for microscopy to detect malaria parasites. Data was analysed using SPSS version 22. Results: The prevalence of placental malaria parasitaemia was $13.7 \%$. Maternal age $<25$ years ( $\mathrm{P}<0.001)$, low educational status $(\mathrm{P}=0.03)$, low parity $(\mathrm{P}=0.03)$, unbooked status $(\mathrm{P}<0.001)$ and non-use of intermittent preventive treatment $(\mathrm{P}<0.001)$ were significantly associated with placental malaria parasitaemia. Receiving three or more doses of sulphadoxine-pyrimethamine for intermittent preventive treatment of malaria in pregnancy was by far, more protective for placental malaria than receiving 2 doses (odds ratio $=0.25$ ). Plasmodium falciparum was the only parasite species detected. Conclusion: Malaria still ravages our obstetric population and the significant contributors include low maternal age, low educational status, low parity, unbooked status and non-use of intermittent preventive treatment in pregnancy. Women should be encouraged to utilize antenatal care. There should be a prompt adoption of the
\end{abstract}


recent WHO recommendations regarding malaria prophylaxis in pregnancy in all obstetric units and the medication should be given as Directly Observed Therapy.

Keywords: Placental malaria, Placental malaria parasitaemia, Placental parasitization

\section{Introduction}

Malaria during pregnancy is a global public health problem that remains a significant threat to the health and survival of the mother, foetus and neonate.(Atta \& Reeder, 2014; World Health Organaization, 2014) The most important complications are maternal anaemia, foetal death and intrauterine growth restriction leading to low birth weight.

The burden is highest in sub-Saharan Africa where it is responsible for $26 \%$ of severe anaemia in pregnancy, and up to 1 out of every 4 women have evidence of placental infection at delivery. It is also responsible for $35 \%$ of preventable low birth weight neonates; 9-fold risk of neonatal death and 3-17 infant deaths per 1000 live births.(Desai et al., 2007)

These Complications are described as consequences of placental sequestration (also called placental malaria).(Autino et al., 2012) Infected erythrocytes have ability to adhere to chondroitin sulphate $A$ on the syncytiotrophoblasts of the placenta(Autino et al., 2012) and because of this placental sequestration, peripheral blood film microscopy underestimates the prevalence of malaria in pregnancy.(Fried et al., 2012) This also is responsible for missed diagnosis and delay in instituting treatment with resultant potentiation of adverse effects of malaria in pregnancy.(Fried et al., 2012) Because of the above, microscopy of placental blood is thus, more sensitive in the diagnosis of maternal malaria than peripheral blood film microscopy.(Fried et al., 2012) More so, the presence of placental malaria parasitaemia at delivery is an indication that placental sequestration was either not prevented, cleared promptly or recurrent because of poor malaria prevention during pregnancy.

The prevalence of placental malaria varies. Using placental blood film microscopy, it averages $25 \%$ in sub-Saharan Africa.(Desai et al., 2007) The prevalence in Nigeria is higher in the South-East region (as high as $64.4 \%$ )(Aribodor et al., 2009) than in other regions (11.3 to 25\%).(Falade et al., 2007; Falade et al., 2010; Inyang-Etoh et al., 2011; Kolawole, 2009; Mokuolu et al., 2009) A recent study (in 2015) at the University of Portharcourt Teaching Hospital however reported an alarming prevalence of $65.2 \%$ among 210 parturients.(Bassey et al, 2015) These variations in prevalence may be due to variations in community acquired immunity, sociodemographic characteristics of study population, case selection, quality of 
antenatal care, use of malaria preventive measures, resistance to antimalarial drugs and diagnostic tools employed for parasite detection.(Bassey et al., 2015)

Documented risk factors for placental malaria include young maternal age, nulliparity/primiparity, non-use of malaria preventive measures and HIV infection.(Bassey et al., 2015; Briand et al., 2009; Oraneli et al., 2013; Tako et al., 2005)

The preventive measures postulated by the World Health Organization include use of insecticide-treated bed nets, intermittent preventive treatment of malaria in pregnancy and effective case management with potent antimalarial drugs.(Olumese, 2014) The current intermittent preventive therapy for malaria during pregnancy as postulated by the Nigerian Federal Ministry of Health in 2014, is the use of at least three doses of sulphadoxinepyrimethamine (SP) combination, given not less than four weeks apart, in the second and third trimesters of pregnancy.(Federal Ministry of Health [Nigeria], 2014) These preventive measures are recommended to be available in every malaria endemic environment.(Olumese, 2014) Meta-analysis of intervention trials(Garner \& Gülmezoglu, 2006) suggests that prevention of malaria in pregnancy (with the above measures) reduces the risk of severe anaemia, LBW and perinatal mortality by $38 \%, 43 \%$ and $27 \%$ respectively. As such, the World Health Organization encourages local research (such as this) and collaboration between scientists, policy makers and health institutions where the control programs are offered. This helps to guide the prevention programs as well as monitor and evaluate markers of successful prevention.

It is hoped that the findings, conclusions and recommendations from this study serve as additional advocacy for the need for policy makers to institute widespread coverage of malaria prevention strategies in pregnancy; attending physicians to ensure adherence to malaria prevention guidelines; and antenatal clients to comply with malaria preventive measures. These will ultimately lead to reduction in malaria associated morbidity and mortality and improvements in maternal, foetal and child health.

\section{Objectives}

The objectives of this study were to determine the prevalence of placental blood malaria parasitaemia at delivery among parturients and determine the risk factors associated with placental malaria parasitization at the Federal Medical Centre, Yenagoa. 


\section{Methodology}

Study location

This study was conducted at the Federal Medical Centre, Yenagoa, the capital city of Bayelsa State in the South-South region of Nigeria.

\section{Study design}

This was a prospective cross-sectional analytical study.

\section{Study Population}

This consisted of both booked and unbooked parturients

\section{Inclusion Criteria}

All pregnant women presenting to the labour ward (for delivery), who give consent to participate in the study.

\section{Exclusion Criteria}

Parturients who declined participation or do not give consent.

\section{Sample size calculation}

The sample size for this study was calculated using the formula for cross-sectional studies(Araoye, 2003) $\mathrm{N}=\left[\mathrm{Z}^{2} \mathrm{P}(1-\mathrm{P})\right] / \mathrm{d}^{2}$, Where, $\mathrm{N}=$ Sample size; $Z=$ Proportion of normal distribution corresponding to the required $(5 \%)$ significance level (which is 1.96); $\mathrm{P}=$ Prevalence of placental malaria parasitaemia, which is $14 \%$ or 0.14 from a previous study(Mokuolu et al., 2009) and $d=$ Degree of accuracy/ precision expected (0.05)

Thus, $\mathrm{N}=1.96^{2} \times 0.14(1-0.14) / 0.05^{2}=185.5$

The sample size was thus calculated to be 186 . Giving allowance for a $10 \%$ attrition rate, the minimum sample size for the study was 205 participants.

The data for this study was collected over a period of five months (August 1, 2016 to December 31, 2016).

\section{Sampling methodology}

Every consecutive parturient who satisfied the eligibility criteria and gave consent was recruited until the sample size was obtained.

\section{Study Protocol}

With the study protocol in mind, standard laboratory methods as described by Cheesbrough(Cheesbrough, 2009) was used. 


\section{Data collection}

After obtaining a signed informed consent from the eligible participant, a semi-structured interviewer-administered questionnaire was filled. The questionnaire contained information that includes maternal age, marital status, educational status, occupation, gravidity, antenatal care, malaria preventive measures, infant birth weight and placental blood microscopy for malaria parasite detection as well as parasite density.

\section{Placental blood collection}

The aspiration method of placental blood collection(Othoro et al., 2006) was employed. This was done immediately after delivery of the placenta. The placenta (with its maternal surface facing up) was placed on a smooth surface. The maternal placental surface was washed with 200 millilitres of normal saline, and pierced (to a depth of about $0.5 \mathrm{~cm}$ ) with a sterile disposable syringe on a 14-gauge hypodermic needle. Two millilitres of placental blood was aspirated and put into an EDTA bottle. The specimen was labelled to correspond with the code on the questionnaire (for easy identification) and sent to the laboratory for processing (smearing, staining and microscopic examination).

\section{Laboratory procedure}

\section{Preparation and staining of the thick blood smear}

Two drops of placental blood sample were placed on a slide using a small rubber pipette. Using the edge of a second slide, the drops of blood were joined and spread to make an even, thick smear and allowed to air-dry. The slide was immersed in the staining trough, containing $10 \%$ of freshly prepared Giemsa solution at $\mathrm{pH} 7.2$ and contact maintained for 10 minutes. The slide was then removed and allowed to dry.

\section{Preparation and staining of the thin blood smear}

One drop of placental blood was placed on a clean slide using a rubber pipette. The edge of a second slide held steadily at an angle of $45^{\circ}$ to the first was used to spread the drop of blood to create the thin blood film. The thin film was fixed using Methanol (methyl alcohol) by maintaining contact with methanol for 10 seconds. The slide was then immersed in the staining trough containing $10 \%$ of freshly prepared Giemsa solution at $\mathrm{pH} 7.2$ and contact was maintained for 10 minutes. The slide was then removed and allowed to dry.

\section{Microscopic examination of slides for malaria parasite and determination of parasite density}

The stained placental blood smears were examined under $\times 100$ oil immersion lens of a light microscope. Malaria diagnosis was based on 
identification of asexual stages of Plasmodium species on the thick blood smear while the thin blood smear was used for species identification.

Parasite density was determined by counting the number of parasites per high power field in the thick blood smear and reported as follows: + (110 parasites per 100 high power fields $),++(11-100$ parasites per 100 high power fields), +++ (1-10 parasites per high power field), and ++++ (>10 parasites per high power field).

The slide was reported as negative if no parasite was identified per 100 high power fields.

\section{Data Analysis}

Data regarding maternal age, marital status, educational status, occupation, parity/gravidity, antenatal care, malaria preventive measures, infant birth weight and placental blood microscopy for malaria parasite detection as well as parasite density was entered and statistical analysis done using statistical software (SPSS for windows ${ }^{\circledR}$ version 22.0, SPSS Inc.; Chicago, USA). Univariate analysis for categorical variables was performed using chi-square test. P value less than 0.05 was taken as being statistically significant.

\section{Ethical Consideration}

Ethical approval for this study was obtained from the ethical review board of the Federal Medical Centre, Yenagoa. A written informed consent was also obtained from every participating woman. Participants were not responsible for funding the tests.

\section{Results}

\section{Maternal socio-demographic characteristics}

The maternal socio-demographic characteristics are shown in Table 1. Two hundred and five parturients participated in the study. Their ages ranged from 14 to $45 y$ ars with a mean age of 29.9 years. The modal age group was 30-34 years followed by the 25-29 years age group. The majority of the parturients had tertiary level of education (53.6\%), were married $(93.7 \%)$ and employed (71.7\%). Christians constituted $95.6 \%$ and the remaining $4.4 \%$ were Muslims. More than half (57.1\%) were of the Ijaw ethnic group; the rest were Ibo (31.7\%), Yoruba (4.9\%), Hausa (1\%) and other Nigerian tribes $(5.3 \%)$. The maternal heights ranged from $1.45 \mathrm{~m}-1.66 \mathrm{~m}$ with an average height of $1.58 \pm 0.05 \mathrm{~m}$. 
Table 1: Maternal socio-demographic characteristics

\begin{tabular}{|c|c|c|}
\hline & Frequency & Percentage \\
\hline \multicolumn{3}{|l|}{ Age group } \\
\hline $10-14$ & 1 & 0.5 \\
\hline $15-19$ & 6 & 2.9 \\
\hline $20-24$ & 32 & 15.6 \\
\hline $25-29$ & 54 & 26.3 \\
\hline $30-34$ & 58 & 28.3 \\
\hline $35-39$ & 50 & 24.4 \\
\hline $40-44$ & 3 & 1.5 \\
\hline $45-49$ & 1 & 0.5 \\
\hline Total & 205 & 100.0 \\
\hline \multicolumn{3}{|l|}{ Educational status } \\
\hline No formal education & 2 & 1.0 \\
\hline Primary & 18 & 8.8 \\
\hline Secondary & 75 & 36.6 \\
\hline Tertiary & 110 & 53.6 \\
\hline Total & 205 & 100.0 \\
\hline \multicolumn{3}{|l|}{ Marital status } \\
\hline Single & 13 & 6.3 \\
\hline Married & 192 & 93.7 \\
\hline Total & 205 & 100.0 \\
\hline \multicolumn{3}{|l|}{ Employment status } \\
\hline Unemployed & 58 & 28.3 \\
\hline Employed & 147 & 71.7 \\
\hline Total & 205 & 100.0 \\
\hline \multicolumn{3}{|l|}{ Religion } \\
\hline Christianity & 196 & 95.6 \\
\hline Islam & 9 & 4.4 \\
\hline Total & 205 & 100.0 \\
\hline \multicolumn{3}{|l|}{ Tribe } \\
\hline Ijaw & 117 & 57.1 \\
\hline Yoruba & 10 & 4.9 \\
\hline Ibo & 65 & 31.7 \\
\hline Hausa & 2 & 1.0 \\
\hline Others & 11 & 5.3 \\
\hline Total & 205 & 100.0 \\
\hline \multicolumn{3}{|l|}{ Maternal height } \\
\hline Less than $150 \mathrm{~cm}$ & 18 & 8.8 \\
\hline $151-160 \mathrm{~cm}$ & 185 & 90.2 \\
\hline Greater than $160 \mathrm{~cm}$ & 2 & 1.0 \\
\hline Total & 205 & 100.0 \\
\hline
\end{tabular}

\section{Obstetric Profile}

As illustrated in Table 2, nearly half (40\%) of the parturients were multiparous. The average parity was 2.13 (Range $=0-6)$. One hundred and eighty one $(88.3 \%)$ parturients were booked while $24(11.7 \%)$ were unbooked. The majority $(76.2 \%)$ booked for antenatal care during the second trimester of 
pregnancy, $8.3 \%$ did so in the first trimester while $15.5 \%$ booked during the third trimester. The average gestational age at booking was $22 \pm 7$ weeks. Of all the parturients, $76.1 \%$ had at least four antenatal clinic visits, $11.7 \%$ had none and corresponded to the unbooked parturients. The average gestational age at delivery was 38.5 \pm 1.9 weeks (Range $=31-42$ weeks); of these, $190(92.7 \%)$ parturients delivered at term, 13(6.3\%) delivered before term and 2(1.0\%) delivered post-term.

Table 2: Obstetric profile

\begin{tabular}{|c|c|c|}
\hline & Frequency & Percentage \\
\hline \multicolumn{3}{|l|}{ Parity } \\
\hline Nulliparous & 57 & 27.8 \\
\hline Primiparous & 58 & 28.3 \\
\hline Multiparous & 82 & 40.0 \\
\hline Grand multiparous & 8 & 3.9 \\
\hline Total & 205 & 100.0 \\
\hline \multicolumn{3}{|l|}{ Booking status } \\
\hline Unbooked & 24 & 11.7 \\
\hline Booked & 181 & 88.3 \\
\hline Total & 205 & 100.0 \\
\hline \multicolumn{3}{|c|}{ Trimester at booking $(n=181)$} \\
\hline First trimester & 15 & 8.3 \\
\hline Second trimester & 138 & 76.2 \\
\hline Third trimester & 28 & 15.5 \\
\hline Total & 181 & 100.0 \\
\hline \multicolumn{3}{|l|}{ Number of ANC visits } \\
\hline None & 24 & 11.7 \\
\hline One & 6 & 2.9 \\
\hline Two & 9 & 4.4 \\
\hline Three & 10 & 4.9 \\
\hline Four and above & 156 & 76.1 \\
\hline Total & 205 & 100.0 \\
\hline \multicolumn{3}{|c|}{ Gestational age at delivery } \\
\hline Preterm & 13 & 6.3 \\
\hline Term & 190 & 92.7 \\
\hline Post term & 2 & 1.0 \\
\hline Total & 205 & 100.0 \\
\hline
\end{tabular}

$\mathrm{ANC}=$ Antenatal Clinic

\section{Malaria control measures (table 3)}

a) Intermittent preventive therapy with SulphadoxinePyrimethamine (IPTpSP): All the 181 booked parturients $(88.3 \%$ of the participants) had IPTpSP; $16.1 \%$ had only one dose, 50.7\% had two doses and $21.5 \%$ had at least, three doses. None of the unbooked parturients $(11.7 \%$ of the participants) had IPTpSP or any other form of malaria chemoprophylaxis. The parturients who booked late in the third trimester (from 32 weeks of gestation and beyond) contributed to the number of women that had just one 
or two doses of IPTpSP, the remainder booked early but were not compliant with the prescription.

b) Insecticide-treated net (ITN) use: About half (50.2\%) of the respondents slept under ITNs but only $30.7 \%$ did so consistently.

c) Other measures: Other forms of vector control/malaria preventive measures used by respondents were indoor residual spraying with insecticides $(72.7 \%)$ and use of mosquito coils (22\%). Majority (98.5\%) of the respondents had door and window nets at home.

d) Malaria case treatment: Fifty nine (28.8\%) respondents were treated for symptomatic malaria during pregnancy. Arthemeter-Lumefantrine combination was the most common antimalarial used by $27.8 \%$ of the respondents while the remaining $1 \%$ took quinine.

Table 3: Malaria control measures

\begin{tabular}{|c|c|c|}
\hline & Frequency & Percentage \\
\hline \multicolumn{3}{|l|}{ IPTpSP } \\
\hline No use & 24 & 11.7 \\
\hline 1 dose & 33 & 16.1 \\
\hline 2 doses & 104 & 50.7 \\
\hline 3 or more doses & 44 & 21.5 \\
\hline \multicolumn{3}{|l|}{ Insecticide Treated Net } \\
\hline No use & 102 & 49.8 \\
\hline Occasional use & 40 & 19.5 \\
\hline Consistent use & 63 & 30.7 \\
\hline \multicolumn{3}{|l|}{ Insecticide spray } \\
\hline Does not use & 56 & 27.3 \\
\hline Uses less than once a week & 58 & 28.3 \\
\hline Uses once a week & 32 & 15.6 \\
\hline Uses twice a week or more & 59 & 28.8 \\
\hline \multicolumn{3}{|l|}{ Mosquito coils } \\
\hline Does not use & 160 & 78.0 \\
\hline Uses less than once a week & 18 & 8.8 \\
\hline Uses once a week & 8 & 3.9 \\
\hline Uses twice a week or more & 19 & 9.3 \\
\hline \multicolumn{3}{|l|}{ Door and window netting } \\
\hline Absent & 11 & 5.4 \\
\hline Present & 194 & 94.6 \\
\hline \multicolumn{3}{|l|}{ Malaria drug treatment } \\
\hline None & 146 & 71.2 \\
\hline Quinine & 2 & 1.0 \\
\hline Artemether/Lumefantrine & 57 & 27.8 \\
\hline
\end{tabular}

\section{Prevalence and pattern of placental malaria parasitaemia}

Two hundred and five placental blood films were analysed. Malaria parasite was detected in 28(13.7\%) placental blood films and all had mild (+) parasitaemia. Plasmodium falciparum was the only malaria species detected in all the placental blood films. 


\section{Risk factors for placental malaria parasitaemia}

As depicted in table 4, maternal age of less than 25 years; primary or no education; nulliparity and primiparity; unbooked status and non-use of intermittent preventive treatment with sulphadoxine-pyrimethamine (IPTpSP) were shown to have a significant association with the detection of malaria parasite in the placental blood sample.

Other risk factors that were assessed and found not to be significantly associated with placental blood parasitaemia were marital status, maternal employment status, husband's educational status, husband's employment status, malaria case treatment in pregnancy, insecticide-treated net (ITN) use, presence of nets on doors and windows at home, use of insecticide sprays and use of mosquito coils.

After multivariate logistic regression analysis, the variables statistically and independently significant were maternal age of less than 25 years [odds ratio $=4.19(1.56-11.22)]$; low parity including nulliparity [odds ratio $=2.7(0.84-8.77)]$ and primiparity $[$ odds ratio $=2.05(0.62-6.75)]$; and non-use of intermittent preventive treatment with sulphadoxinepyrimethamine [odds ratio $=3.43(1.07-11.00)$ ]

Table 4: Risk factor analysis

\begin{tabular}{|c|c|c|c|c|c|c|c|}
\hline & $\begin{array}{l}\mathrm{MP}+\mathrm{ve} \\
\mathrm{N}(\%)\end{array}$ & $\begin{array}{l}\text { MP-ve } \\
\mathrm{N}(\%)\end{array}$ & $\begin{array}{c}\text { Total } \\
\mathrm{N}\end{array}$ & OR(95\% CI) & $X^{2}$ & $\mathrm{df}$ & $\begin{array}{c}\mathrm{P}- \\
\text { value }\end{array}$ \\
\hline Age group & & & & & 15.81 & 1 & $0.00^{*}$ \\
\hline$<25$ years & $13(33.3)$ & $26(66.7)$ & 39 & $5.03(2.15-11.79)$ & & & \\
\hline$\geq 25$ years & $15(9.0)$ & $151(91.0)$ & 166 & & & & \\
\hline $\begin{array}{c}\text { Educational } \\
\text { status }\end{array}$ & & & & & 5.02 & 1 & $0.03^{*}$ \\
\hline Primary or less & $6(30.0)$ & $14(70.0)$ & 20 & & & & \\
\hline $\begin{array}{c}\text { At least } \\
\text { secondary }\end{array}$ & $22(11.9)$ & $163(88.1)$ & 185 & $0.32(0.11-0.91)$ & & & \\
\hline Marital status & & & & & 0.35 & 1 & 0.69 \\
\hline Single & $2(15.4)$ & $11(84.6)$ & 13 & $0.86(0.18-4.12)$ & & & \\
\hline Married & $26(13.5)$ & $166(86.5)$ & 192 & & & & \\
\hline $\begin{array}{c}\text { Employment } \\
\text { status }\end{array}$ & & & & & 0.53 & 1 & 0.39 \\
\hline Unemployed & $6(10.3)$ & $52(89.7)$ & 58 & & & & \\
\hline Employed & $22(15.0)$ & $125(85.0)$ & 147 & $0.66(0.39-1.17)$ & & & \\
\hline $\begin{array}{l}\text { Husband's } \\
\text { educ. Stat. }\end{array}$ & & & & & 0.38 & 1 & 0.54 \\
\hline Primary or less & $2(20.0)$ & $8(80.0)$ & 10 & $1.65(0.33-8.22)$ & & & \\
\hline $\begin{array}{c}\text { At least } \\
\text { secondary }\end{array}$ & $24(13.2)$ & $158(86.8)$ & 182 & & & & \\
\hline $\begin{array}{l}\text { Husband's } \\
\text { empl. Stat. }\end{array}$ & & & & & 0.32 & 1 & 0.57 \\
\hline Unemployed & $0(0.0)$ & $2(100.0)$ & 2 & & & & \\
\hline Employed & $26(13.7)$ & $164(86.3)$ & 190 & & & & \\
\hline
\end{tabular}




\begin{tabular}{|c|c|c|c|c|c|c|c|}
\hline Parity & & & & & 6.89 & 2 & $0.03^{*}$ \\
\hline Nulliparous & $10(17.5)$ & $47(82.5)$ & 57 & $2.98(1.02-8.70)$ & & & \\
\hline Primiparous & $12(20.7)$ & $46(79.3)$ & 58 & $3.65(1.28-10.37)$ & & & \\
\hline Multiparous & $6(6.7)$ & $84(93.3)$ & 90 & & & & \\
\hline Booking status & & & & & 18.08 & 1 & $0.00^{*}$ \\
\hline Unbooked & $10(41.7)$ & $14(58.3)$ & 24 & $6.47(2.51-16.66)$ & & & \\
\hline Booked & $18(9.9)$ & 163(90.1) & 181 & & & & \\
\hline IPTpSP use & & & & & 18.08 & 1 & $0.00 *$ \\
\hline No & $10(41.7)$ & $14(58.3)$ & 24 & $6.47(2.51-16.66)$ & & & \\
\hline Yes & $18(9.9)$ & $163(90.1)$ & 181 & & & & \\
\hline IPTpSP dose & & & & & 10.62 & 2 & $0.01 *$ \\
\hline One & $8(24.2)$ & $25(75.8)$ & 33 & $\begin{array}{c}13.76(1.63- \\
116.54) \\
\end{array}$ & & & \\
\hline Two & $9(8.7)$ & $95(91.3)$ & 104 & $4.07(0.50-33.17)$ & & & \\
\hline $\begin{array}{c}\text { Three and } \\
\text { above }\end{array}$ & $1(2.3)$ & $43(97.7)$ & 44 & & & & \\
\hline ITN use & & & & & 0.71 & 1 & 0.40 \\
\hline No & $16(15.7)$ & $86(84.3)$ & 102 & $1.41(0.63-3.15)$ & & & \\
\hline Yes & $12(11.7)$ & $91(88.3)$ & 103 & & & & \\
\hline $\begin{array}{c}\text { Insecticide } \\
\text { spray }\end{array}$ & & & & & 0.38 & 1 & 0.54 \\
\hline No & $9(16.1)$ & $47(83.9)$ & 56 & $1.31(0.55-3.10)$ & & & \\
\hline Yes & $19(12.8)$ & $130(87.2)$ & 149 & & & & \\
\hline $\begin{array}{c}\text { Mosquito coil } \\
\text { use }\end{array}$ & & & & & 1.95 & 1 & 0.16 \\
\hline No & $24(15.6)$ & $130(84.4)$ & 154 & $2.17(0.72-6.58)$ & & & \\
\hline Yes & $4(7.8)$ & $47(92.2)$ & 51 & & & & \\
\hline $\begin{array}{c}\text { Door/window } \\
\text { netting }\end{array}$ & & & & & 2.30 & 1 & 0.13 \\
\hline No & $0(0.0)$ & $11(100.0)$ & 11 & $2.52(0.74-8.54)$ & & & \\
\hline Yes & $28(14.4)$ & $166(85.6)$ & 194 & & & & \\
\hline $\begin{array}{l}\text { Malaria drug } \\
\text { treat. }\end{array}$ & & & & & 0.86 & 1 & 0.36 \\
\hline No & $22(15.1))$ & $124(84.9)$ & 146 & $1.57(0.60-4.09)$ & & & \\
\hline Yes & $6(10.2)$ & $53(89.8)$ & 59 & & & & \\
\hline
\end{tabular}

$\mathrm{MP}=$ Placental malaria parasitaemia; $\mathrm{OR}=$ Odds Ratio; $\mathrm{CI}=$ confidence interval; $\mathrm{X}^{2}=\mathrm{Chi}$ square value

$\mathrm{df}=$ Degree of freedom; $*$ = significant association $(\mathrm{P}<0.05)$; empl. Stat.= employment status; educ. Stat. $=$ educational status; IPTpSP $=$ intermittent preventive treatment with sulphadoxine-pyrimethamine;

ITN $=$ Insecticide-Treated Net; treat $=$ treatment

\section{Discussion}

The socio-demographic profile of the participants showed patronage from the more educated and affluent women. It is likely that, because of the higher hospital charges in tertiary hospitals, a good number of the less educated and poorer women patronize the primary and secondary health care centres with lower hospital charges. The predominant tribe and religion in the 
area of study were Ijaw and Christianity respectively; this was reflected in the preponderance of Ijaw and Christian women in the study. The older maternal age predominance may have also accounted for the preponderance of parturients that were multiparous.

Concerning the utilization of malaria preventive measures among the parturients, the contributory factors to the non-use of malaria chemoprophylaxis with sulphadoxine-pyrimethamine as well as use of less than three doses in the course of pregnancy include unbooked status, late booking and non-adherence to prescription. While it is possible to have women book early for antenatal care by ensuring female education and empowerment, administration of sulphadoxine-pyrimethamine as directly observed therapy (DOTS) during antenatal visits would prevent noncompliance to the medication. Because pregnant women in malaria endemic areas are among the most vulnerable to the infection, the World Health Organization has recommended that all pregnant women should consistently sleep under insecticide treated bed nets.(Olumese, 2014) According to the Nigerian Demographic Survey of 2013, only 18\% of pregnant women slept under insecticide treated bed net the night before the survey (an index for its consistent use).(National Population Commission [Nigeria] and ICF International, 2013) Although the result from this study (30\% rate of consistent use) is an improvement from the 2013 findings, it is still below the recommendation of consistent use among all (100\%) pregnant women in malaria endemic regions.

The prevalence of placental malaria parasitaemia of $13.7 \%$ found in this study is similar to the prevalence of $14 \%$ reported by Mokuolu et al in a study from four geopolitical zones in Nigeria(Mokuolu et al., 2009) and that $(13.0 \%)$ reported by Falade et al in south western Nigeria(Falade et al., 2010) but much lower than the $65.2 \%$ prevalence reported in Portharcourt (Bassey et al., 2015) within the same geographical zone with Bayelsa where this study was conducted. The lower prevalence in this study may be due to the high level of education among the parturients which may have contributed to their health awareness with a positive impact on their health and the effective malaria preventive measures utilized by the parturients including IPTpSP (88.3\%) and ITN (50.2\%); other factors may include a high level of community acquired immunity and the quality of antenatal care.(Bassey et al., 2015)

The finding that Plasmodium falciparum was the only parasite species detected in all the placental blood films in this study confirms previous reports that placental malaria is an exclusive feature of plasmodium falciparum infection in pregnancy(Srivastava et al., 2010) and that Plasmodium falciparum is the most prevalent species in Nigeria accounting for about $98 \%$ of malaria cases in the country(Federal Ministry of Health [Nigeria], 2010) 
This study identified maternal age less than 25 years, less than secondary level of education, low parity (nulliparity and primiparity), unbooked status and non-use of malaria chemoprophylaxis (sulphadoxinepyrimethamine) as risk factors for placental malaria parasitaemia. Parturients younger than 25 years of age were 5 times more likely to have placental malaria parasitaemia than those 25 years and older. This supports the findings of previous studies stating young maternal age as a risk factor for placental malaria(Idowu \& Babalola, 2015; Mokuolu et al., 2009; Okolie et al., 2014) which could be attributed to lower levels of acquired immunity as well as the lack of pregnancy associated immunity against the placental-binding parasites.(Idowu \& Babalola, 2015)

As observed in the study and although not an independent risk factor, parturients who had none or primary level of education were 3 times more likely to have placental malaria compared to parturients with at least secondary level of education. High educational standards usually affect health awareness and therefore has a positive impact on health.(Ogbu et al., 2015) The reverse may be the case in those with lower standards of education as they may not appreciate the burden of malaria in pregnancy and the importance of adherence to stipulated malaria preventive measures because of their limited understanding and knowledge.

Multiparous women in malaria-endemic regions are believed to form blocking antibodies that bind to placental chondroitin sulphate A during their subsequent pregnancies and prevent placental sequestration of Plasmodium falciparum.(Maestre \& Carmona-Fonseca, 2014) This explains why the burden of malaria in pregnancy is higher among women of low parity (nulliparity and primiparity) and is supported by findings from this study that demonstrated low parity as an independent risk factor for placental malaria parasitaemia. The result suggested that nulliparous and primiparous women individually had a three-fold risk for placental malaria compared to multiparous women. Similar findings have been reported by researchers in Portharcourt, Nnewi and Ile Ife in Nigeria.(Bassey et al., 2015; Fehintola et al., 2016; Okolie et al., 2014)

As a component of the malaria preventive measures during pregnancy, the Nigerian Federal Ministry of Health has recommended the use of at least three doses of sulphadoxine-pyrimethamine combination with each dose given not less than 4 weeks apart in the second and third trimesters of pregnancy.(Federal Ministry of Health [Nigeria], 2014) Not receiving intermittent preventive treatment in pregnancy, identified as an independent risk factor in this study increased the risk of placental malaria parasitaemia by six times compared to those that received. Several studies have reported similar findings.(Bassey et al., 2015; Fehintola et al., 2016; Idowu \& Babalola, 2015) Also, among the parturients who had malaria chemoprophylaxis with at 
least a dose of sulphadoxine-pyrimethamine combination during pregnancy, receiving at least three doses was more protective than receiving 2 doses (Odds Ratio of 0.25 ) or one dose (Odds Ratio of 0.07). The contributory factors for receiving less than the recommended doses include unbooked status, late booking, non- compliance with prescription and possibly, unavailability of the medication at the time of desired purchase from pharmacy stores (as at the time of this study, the drug was not being administered as directly observed therapy in the study location). Provision of the medication at the antenatal clinic and administration as directly observed therapy (DOT) coupled with adequate female education and empowerment would likely eliminate the above stated factors.

While several studies have demonstrated the non-use of insecticide treated bed nets by pregnant women as a risk factor for placental malaria parasitaemia,(Ezebialu et al., 2012; Idowu \& Babalola, 2015) this study did not. A common habit in the study area of sitting out till late at night before retiring to sleep in a bid to 'get fresh air' and avoid the heat inside the houses especially during the protracted periods of interrupted power supply that prevents the use of fans or air conditioners, is likely to expose individuals to mosquito bites and undermine the effectiveness of sleeping under insecticide treated bed nets. This may explain the contrary finding in this study.

Malaria in pregnancy is still a public health problem. The level of utilization of the preventive measures is still far from what is desired. The results of this study, adds justification for advocacy from all stakeholders to promote the utilization of malaria preventive measures during pregnancy in order to achieve a reduction in the burden of the disease.

\section{Conclusion}

Malaria during pregnancy is still an important public health problem in our obstetric population with a high prevalence of placental malaria parasitaemia and the significant contributors include low maternal age, low educational status, low parity, unbooked status and non-use of intermittent preventive treatment in pregnancy. Women should be educated and empowered financially and encouraged to register for antenatal care during pregnancy. There should be a prompt switch to the recent WHO recommendation regarding malaria prophylaxis in pregnancy and the medication should be given as Directly Observed Therapy.

\section{References:}

1. Araoye M. Sample size determination. In: Research Methodology with Statistics for Health and Social Sciences. Ilorin: Nathadex publishers; 2003. pages 115-121.

2. Aribodor DN, Nwaorgu OC, Eneanya CI, Okoli I, Pukkila-Worley R, 
Etaga HO. Association of low birth weight and placental malarial infection in Nigeria. J Infect Dev Ctries. 2009;3(8):620-3.

3. Atta H, Reeder J. World Malaria Day 2014: Invest in the future. Defeat malaria. East Mediterr Heal J. 2014;20(4):219-20.

4. Autino B, Corbett Y, Castelli F, Taramelli D. Pathogenesis of malaria in tissues and blood. Mediterr $\mathrm{J}$ Hematol Infect Dis. 2012;4(1):e2012061.

5. Bassey G, Nyengidiki TK, John CT. Prevalence of placenta Plasmodium parasitemia and pregnancy outcome in asymptomatic patients at delivery in a University Teaching Hospital in Nigeria. Niger J Clin Pract. 2015;18(1):27-32.

6. Briand V, Badaut C, Cot M. Placental malaria, maternal HIV infection and infant morbidity. Ann Trop Paediatr. 2009;29(2):71-83.

7. Cheesbrough M. District Laboratory Practice in Tropical Countries :Part 1. 2nd ed. Parasitological tests. Cambridge University Press, New York.; 2009. pages 244-251.

8. Desai M, ter Kuile FO, Nosten F, McGready R, Asamoa K, Brabin B, et al. Epidemiology and burden of malaria in pregnancy. Lancet Infect Dis. 2007 Feb;7(2):93-104.

9. Ezebialu IU, Eke AC, Ezeagwuna D a., Nwachukwu CE, Ifediata F, Ezebialu CU. Prevalence, pattern, and determinants of placental malaria in a population of southeastern Nigerian parturients. Int $\mathbf{J}$ Infect Dis. 2012;16(12):e860-5.

10. Falade C, Mokuolu O, Okafor H, Orogade A, Falade A, Adedoyin O, et al. Epidemiology of congenital malaria in Nigeria: A multi-centre study. Trop Med Int Heal. 2007;12(11):1279-87.

11. Falade CO, Tongo OO, Ogunkunle OO, Orimadegun AE. Effects of malaria in pregnancy on newborn anthropometry. J Infect Dev Ctries. 2010;4(7):448-53.

12. Federal Ministry of Health (FMoH). National diagnosis and treatment policy. Abuja -Nigeria: Federal Ministry of Health Nigeria, National Malaria and Vector Control Division [Internet]. 2010 [cited 2016 Jun 3]. Available from: www.nmcp.gov.ng

13. Federal Ministry of Health (FMoH). National Guidelines and Strategies for Malaria Prevention and Control During Pregnancy [Internet]. 2nd ed. Federal Ministry of Health, Nigeria; 2014 [cited 2016 Jun 4]. Available from: www.nmcp.gov.ng

14. Fehintola AO, Fehintola FO, Loto OM, Fasubaa OB, Bakare B, Ogundele O. Pregnancy and fetal outcome of placental malaria parasitemia in Ile-Ife, Nigeria. Trop J Obstet Gynaecol. 2016;33(3):310.

15. Fried M, Muehlenbachs A, Duffy PE. Diagnosing malaria in 
pregnancy: an update. Expert Rev Anti Infect Ther. 2012;10(10):1177-87.

16. Garner P, Gülmezoglu a M. Drugs for preventing malaria in pregnant women. Cochrane Database Syst Rev. 2006;(4):CD000169.

17. Idowu OA, Babalola AS. Risk factors associated with occurrence of placenta malaria in a population of parturients in Abeokuta Ogun State, Nigeria. 2015;6(8):1-6.

18. Inyang-Etoh $\mathrm{E}$, Etuk $\mathrm{S}$, Agan $\mathrm{T}$, Inyang-Etoh $\mathrm{P}$. The role of prophylactic antimalarial in the reduction of placental parasitemia among pregnant women in Calabar, Nigeria. Niger Med J. 2011;52:235-8.

19. Kolawole OM. Prevalence of Congenital Malaria in Ilorin, Nigeria. Index African Journals Online www.ajol.info An Int MultiDisciplinary J. 2009;3(1):1994-9057.

20. Maestre A, Carmona-Fonseca J. Immune responses during gestational malaria: a review of the current knowledge and future trend of research. J Infect Dev Ctries. 2014;8(4):391-402.

21. Mokuolu OA, Falade CO, Orogade AA, Okafor HU, Adedoyin OT, Oguonu TA, et al. Malaria at parturition in Nigeria: current status and delivery outcome. Infect Dis Obs Gynecol. 2009;2009(7):473971.

22. National Population Commission (NPC) [Nigeria] and ICF International. Malaria. In: Nigeria Demographic and Health Survey 2013 National Population Commission Federal Republic of Nigeria. 2013. pages 201-21.

23. Ogbu GI, Aimakhu CO, Anzaku SA, Ngwan S, Ogbu DA. Prevalence of malaria parasitaemia among asymptomatic women at booking visit in a tertiary hospital, North- central Nigeria. J Reprod Biol Heal ISSN. 2015;3(1):2054-841.

24. Okolie VE, Obiechina NJ, Okechukwu ZC, Oguejiofor CF. Prevalence and Risk Factors for Placental Malaria in Nnewi, South East Nigeria. 2014;4(3):374-83.

25. Olumese P. Malaria Control: WHO Technical Updates [Internet]. Geneva, Switzerland: World Health Organization; 2014 [cited 2016 Jun 6]. Available from: rbm.acw-server1.co.uk/.../WHO Key technical updates pres 2.pdf

26. Oraneli BU, Okeke OC, Ubachukwu PO. Effect of placental malaria on birth weight of babies in Nnewi, Anambra state, Nigeria. J Vector Borne Dis. 2013;50(1):13-7.

27. Othoro C, Moore JM, Wannemuehler K, Nahlen BL, Otieno J, Slutsker $\mathrm{L}$, et al. Evaluation of various methods of maternal placental blood collection for immunology studies. Clin Vaccine Immunol. 2006;13(5):568-74. 
28. Srivastava A, Gangnard S, Round A, Dechavanne S, Juillerat A, Raynal B, et al. Full-length extracellular region of the var2CSA variant of PfEMP1 is required for specific, high-affinity binding to CSA. Proc Natl Acad Sci U S A. 2010;107(11):4884-9.

29. Tako E a., Zhou A, Lohoue J, Leke RFG, Taylor DW, Leke RFG. Risk factors for placental malaria and its effect on pregnancy outcome in Yaounde, Cameroon. Am J Trop Med Hyg. 2005;72(3):236-42.

30. World Health Organaization (WHO). World malaria report 2014 [Internet]. World Health Organisation. Geneva, Switzerland; 2014 [cited 2016 Jun 4]. Available from: http://www.who.int/malaria/publications/world_malaria_report_2014 len/ 